\title{
Are lower urinary tract symptoms in men associated with cardiovascular diseases in a primary care population: a registry study
}

\author{
Inge I Bouwman ${ }^{1 *+}$, Boudewijn J Kollen ${ }^{1 \dagger}$, Klaas van der Meer ${ }^{1}$, Rien JM Nijman ${ }^{2}$ and Wouter K van der Heide ${ }^{1 \dagger}$
}

\begin{abstract}
Background: Although lower urinary tract symptoms (LUTS) seem to be related to cardiovascular disease (CVD) in men, it is unclear whether this relationship is unbiased. In order to investigate this relationship, we used longitudinal data for establishing the possible predictive value of LUTS for the development of CVD in a primary care population.
\end{abstract}

Methods: We performed a registry study using data from the Registration Network Groningen (RNG). All data from men aged 50 years and older during the study period from 1 January 1998 up to 31 December 2008 were collected. Cox proportional hazard regression analysis was used to determine the association between the proportions of CVD (outcome) and LUTS in our population.

Results: Data from 6614 men were analysed. The prevalence of LUTS increased from 92/1000 personyears (py) in 1998 up to 183/1000 py in 2008. For cardiovascular diseases the prevalence increased from 176/1000 py in 1998 up to $340 / 1000$ py in 2008 . The incidence numbers were resp. $10.2 / 1000$ py (1998) and 5.1/1000 py (2008) for LUTS, and $12.9 / 1000$ py (1998) and 10.4/1000 py (2008) for CVD. Of all men, 23.2\% reported CVD (41.1\% in men with LUTS vs $19.5 \%$ in men without LUTS, $\mathrm{p}<0.01$ ). The hazard ratio of LUTS for cardiovascular events, compared to no LUTS, in the adjusted multivariate model, was 0.921 (95\% Cl: $0.824-1.030 ; p=0.150)$.

Conclusion: Based on the results, LUTS is not a factor that must be taken into account for the early detection of CVD in primary care.

\section{Background}

Cardiovascular diseases (CVD) are a major cause of morbidity and mortality. Worldwide, CVD is responsible for an estimated 35 million deaths each year [1,2].

The recently published guidelines 'Prevention of cardiometabolic diseases' [3] urge general practitioners (GPs) to play a proactive role in secondary prevention of their patients at risk, and to manage subsequent intervention $[3,4]$. Identifying associated morbidities that may precede CVD could assist the GP in this role.

Research in the past decade has revealed an association between CVD and erectile dysfunction (ED) in community based and clinical studies [5-7]. The incidence of coronary

\footnotetext{
* Correspondence: iibouwman@hotmail.com

${ }^{\dagger}$ Equal contributors

${ }^{1}$ Department of general practice, University of Groningen, University Medical Center Groningen, Antonius Deusinglaan 1, Groningen, AV 9713, Netherlands Full list of author information is available at the end of the article
}

heart diseases in Dutch men, in 2007, increases from $5 / 1000$ men aged 50 up to 30/1000 men aged 80 [3]. The incidence of ED in general practice is, however, low (1.7/1000 men/year) [8]; using ED to help identify patients at risk for CVDs will not improve the efficacy of prevention activities. On the other hand ED is also associated with Lower Urinary Tract Symptoms (LUTS) in both community and clinically based populations [9-13]. The incidence of LUTS in the general practice population increases with age, from 2.2 in men aged $<45$ years up to $18.7 / 1000$ patients/year for men aged 85 years and older [14-16]. For the GP, it is therefore a more useful instrument in case finding of individuals with CVD than ED (incidence in primary care population: 1.7/1000 patients/year, increasing up to 5.6/1000 patients/year for men aged 65-74 years [8]). A few clinical studies have reported a cross-sectional relationship between LUTS and CVD [17-26]. Also, in one community based longitudinal study, a longitudinal

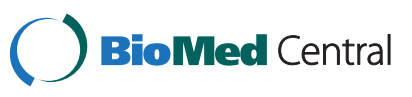


relationship between LUTS and CVD was found [25]. However, the relationship between LUTS and CVD has not yet been demonstrated in a primary care setting.

LUTS and CVD share some risk factors such as obesity, diabetes, hypertension, smoking, and ageing $[23,24]$. The underlying pathophysiological relationship could be explained by fluid shifts, hormonal and autonomic nervous disturbances caused by hypertension and heart failure, but also by waking due to nycturia [17-26]. Endothelial dysfunction in the pelvic vascular system might contribute to bladder dysfunction with rising age [5]. Also, diabetes mellitus can lead to LUTS via neurogenic bladder dysfunction with detrusor underactivity [5].

The hypothesis that LUTS could be associated with the development of CVD still needs to be confirmed in primary care. The only evidence to date is one longitudinal, community-based study conducted on a small group of men with severe LUTS [25]. Therefore, the objective of our study is to explore the relationship between LUTS and CVD in a primary care population.

\section{Methods}

We performed a registry study using data from the Registration Network Groningen (RNG), one of several registration networks in the Netherlands. These registration networks carry out research on data derived from the electronic registration of daily patient care in their participating general practices. The Registration Network Groningen was established in 1989, and has three practices in the north of the Netherlands, with an annual population of approximately 30,000 patients [27].

In the Netherlands, the GP is the gatekeeper in the Dutch health-care system controlling access to specialized medical care. Virtually all non-institutionalized Dutch citizens are registered with a GP so the total practice population represents the general population [28].

GPs working in the RNG-practices use a structured medical record, in which all patient contacts are registered. This includes reason for encounter, medical diagnosis (according to the International Classification of Primary Care (ICPC) [29]), applied treatment (among which prescriptions, using the Anatomical Therapeutic Chemical (ATC) codes [30], and referrals), but also cause of death. The database also includes population dynamics, such as date of entry and departure from the database.

From the RNG registration, we selected all data from men aged 50 years and older (age at any time during the study period: 1January 1998-31 December 2008).

Patients with a history of Prostate Cancer, as well as men with a history of CVD were excluded for longitudinal analysis. Access to the patient's medical history was a prerequisite. We collected the following data from the registration: date of birth, date of entry in the study, date of and reason for leaving the registration, GP code, patient contacts (ICPC codes), prescriptions (ATC codes) and ICPC codes attached to these medications, and hospital referrals. From this information, we calculated age from date of birth and number of person years in study. All of the data were anonymised. We received ethical permission to access the Registration Network Groningen from the Medical Ethical Research Board, University Medical Center Groningen (M13.132482).

\section{Definitions}

Cardiovascular event is defined as a documented acute myocardial infarction, chronic ischaemic heart disease, transient ischemic attack or stroke in the medical records of the GPs [31]. Table 1 provides the ICPC codes as registered by the RNG-GPs that were used for this study and recode this according to the ICPC. For each participant, we defined CVD-status at baseline (01-01-1998), or at date of study entry, as being present (previous cardiovascular event before inclusion in the study) or absent.

Lower urinary tract symptoms (LUTS) include the sensation of not urinating completely, withholding urinating, and difficulty voiding. This may include having a stopand-go urinary flow and getting up frequently at night

Table 1 Definitions of study parameters and ICPC codes

\begin{tabular}{|c|c|}
\hline Study parameter & ICPC code and definition \\
\hline $\begin{array}{l}\text { Lower urinary tract } \\
\text { symptoms }\end{array}$ & $\begin{array}{l}\text { U02: frequency, U05: other voiding symptoms, } \\
\text { U07: other symptoms, U13: other symptoms } \\
\text { bladder, U29: other symptoms urinary tract, } \\
\text { Y06: symptoms prostate, Y85: benign prostate } \\
\text { hypertrophy }\end{array}$ \\
\hline Erectile dysfunction & Y07: symptoms sexual potential \\
\hline $\begin{array}{l}\text { Cardiovascular } \\
\text { diseases }\end{array}$ & $\begin{array}{l}\text { K74: angina pectoris, K75: acute myocardial } \\
\text { infarction, K76: other chronic ischaemic heart } \\
\text { disease, K89: transient ischaemic attaque, } \\
\text { K90: cerebrovascular accident }\end{array}$ \\
\hline
\end{tabular}

Cardiovascular risk $\quad$ K86: hypertension without organ damage, K87: factors hypertension with organ damage, T82 obesity Quetelet Index > 30, T83: obesity QI < 30, P17: smoking, P15: chronic alcohol abuse, T93: dislilpydemia

Medication

LUTS medication: selective a-1 receptor blockers, 5a1-reductase inhibitors

Antipsychotics

Opiates

Antidiabetics: oral and insulin therapy

Antihypertensives: ACE inhibitors, All receptor blockers, B-blockers, Calcium antagonists, diuretics

Cholesterol reducing drugs

Anti Impotence pills

Parkinson medication

Tricyclic antidepressants

Anticoagulant drugs 
to urinate [32]. There is no specific ICPC code for LUTS, therefore we defined LUTS by all relevant ICPC codes or use of LUTS medication (Table 1).

Erectile dysfunction is defined as the persistent inability to achieve or maintain an erection suficient for satisfactory sexual performance [33], in this study defined by the ICPC code Y07: symptoms sexual potential.

\section{Statistical analysis}

Descriptive statistics were used to compare the baseline characteristics. Continuous variables are presented in means and confidence intervals, and nominal variables reported in modi. Prevalences (and incidence numbers for LUTS and CVD) for LUTS, CVD, hypertension, Erectile dysfunction, and Diabetes mellitus were calculated by means of prevalence/1000 personyears for the first and last studyyear (1998 and 2008).

Cox proportional hazard regression analysis was used to determine the association between the proportions of CVD (outcome) and LUTS in our population. We used age as time factor in a Cox proportional hazard regression analysis to determine the association between CVD (outcome) and LUTS in our population. In this open cohort, time to event (CVD) was calculated from the patient's date of birth to event (i.e. diagnosis of LUTS) and data of subjects were censored in case leaving the cohort, death, or end of study.

Initially, an unadjusted analysis was performed. This association regression model was subsequently corrected for confounders. A covariate was considered a confounder in the event the beta coefficient of LUTS changed by 10 or more percent [34].

In this analysis, the following potential confounders [35] were tested: hypertension, diabetes mellitus, obesity, dyslipidaemia, depression, and antihypertensive (ACE-inhibitors, all antagonists, beta blockers, calcium antagonists, and diuretics), and statins.

In all analyses, multiple dummy variables were created for the analyses of categorical data. In addition, model assumptions were tested for compliance. All analyses were performed using SPSS version 16 based on a two-sided 0.05 significance level.

\section{Results}

\section{Descriptives}

From the database, we collected data from 6614 eligible men. Of these, 1165 (17.6\%) reported LUTS during the study period. Table 2 describes the patient characteristics, for the total sample, and for men with and without LUTS. The prevalence of LUTS increased from 92/1000 personyears (py) in 1998 up to $183 / 1000$ py in 2008. The incidence numbers of LUTS were $10.2 / 1000$ py in 1998 and 5.1/ 1000 py in 2008.

From all men, 1539 had cardiovascular diseases during the study period: $23.2 \%$ (95\% CI $22.2-24.2 \%)(41.1 \%$ in men with LUTS vs $19.5 \%$ in men without LUTS, $\mathrm{p}<0.01$ ). The incidence numbers for CVD were $12.9 / 1000$ py in 1998 and $10.4 / 1000$ py in 2008.

Table 3 shows the outcome of LUTS and CVD by agegroups among the study population. Both LUTS and CVD are more prevalent in the highest age group. The prevalence of CVD increased from 176/1000 py in 1998 up to $341 / 1000$ py in 2008 . From all men $26.5 \%$ had hypertension, significantly more prevalent in the LUTS group (40.2\% in men with LUTS vs. $23.5 \%$ in men without LUTS, $p<0.01$ ). The prevalence of hypertension increased during the study period, from 206/1000 py in 1998 up to $387 / 1000$ py in 2008. Also Erectile Dysfunction was more prevalent in the LUTS group $(2.8 \%$ in men with LUTS vs. $1.0 \%$ in men without LUTS, $\mathrm{p}<0.01)$. The prevalence of ED increased from $17 / 1000$ py in 1998 up to $19 / 1000$ py in 2008 during the period 1998-2008. Diabetes mellitus was prevalent in $5.7 \%$ of all men, the prevalence increased from $24 / 1000$ py in 1998 up to $82 / 1000$ py in 2008 . The prevalence of DM was not significantly $(\mathrm{p}=0.85)$ different in the LUTS group compared to the non-LUTS group. Dyslipidemia was prevalent in $20.4 \%$ of all patients. It was significant more prevalent in the LUTS group ( $p$ 0.005) than in the non LUTS group. The prevalences of lifestyle factors as obesity, smoking, alcohol abuse were 3.9, 13.4, and $3.8 \%$ respectively. There were no significant differences between the LUTS and non-LUTS group for lifestyle factors ( $\mathrm{p}$-values are $0.42,0.52$, and 0.18 respectively).

\section{Longitudinal analysis}

There is a significant unadjusted univariate relationship between the proportions cardiovascular events and LUTS (HR 1.16, 95\% CI: 1.035 - 1.291; $\mathrm{p}=0.010)$. However, the hazard ratio of LUTS for cardiovascular events, compared to no LUTS, in the adjusted multivariate model, was nonsignificant $(\mathrm{HR}=0.921,95 \% \mathrm{CI}: 0.824-1.030 ; \mathrm{p}=0.150)$. Therefore, men with LUTS were not more likely to develop CVD, at any time, than men without LUTS. In our analysis, hypertension, ACE-inhibitors, All antagonists, beta blockers, and calcium antagonists were found to confound this relationship. In this population, cardiovascular disease was not associated with LUTS (Table 4).

\section{Discussion}

\section{Main findings}

Nowadays, when a patient consults his general practitioner for LUTS, it is not customary to search for comorbidities such as CVD. However Dynamic cohort and clinical studies suggest a correlation between LUTS and CVD. To the best of our knowledge this is the first study that has been done to establish the relationship between LUTS and CVD in a primary care population. This is an important population because the GP plays an increasingly prominent role with respect to the early detection of patients at risk, for 
Table 2 Population characteristics

\begin{tabular}{|c|c|c|c|c|}
\hline Characteristics & $\begin{array}{c}\text { All men } \\
(n=6614)(\%)\end{array}$ & $\begin{array}{l}\text { Men without LUTS } \\
(n=5449)(82.4 \%)\end{array}$ & $\begin{array}{c}\text { Men with LUTS } \\
(n=1165)(17.6 \%)\end{array}$ & $p$-value \\
\hline Age, mean (SD), y & $56(12)$ & $54(11)$ & $65(12)$ & \\
\hline Report of cardiovascular disease $\left({ }^{*} 1\right)$ & $1539(23.2)$ & 1060(19.5) & $479(41.1)$ & $0.000^{*}$ \\
\hline Report of hypertension (K86 + K87) & $1751(26.5)$ & $1283(23.5)$ & $468(40.2)$ & $0.000^{*}$ \\
\hline Report of erectile dysfunction $\left({ }^{*} 2\right.$ ) & $89(1.3)$ & $56(1.0)$ & $33(2.8)$ & $0.000^{*}$ \\
\hline Report of diabetes mellitus (T90) & $368(5.7)$ & $286(5.2)$ & $92(7.9)$ & $0.000^{*}$ \\
\hline Report of obesity & $260(3.9)$ & 204(3.7) & $56(4.8)$ & 0.090 \\
\hline Report of current smoking & $884(13.4)$ & $751(13.8)$ & 133(11.4) & $0.031^{*}$ \\
\hline Report of alcohol abuse & 254(3.8) & $230(4.2)$ & $24(2.1)$ & $0.000^{*}$ \\
\hline Report of dislipydemia & $1350(20.4)$ & 1046(19.2) & $304(26.1)$ & $0.000^{*}$ \\
\hline Use of LUTS medication ${ }^{*} 3$ ) & $7242(10.9)$ & $5(0.1)$ & $717(61.5)$ & $0.000^{*}$ \\
\hline Use of DM medication (*4) & $29(0.4)$ & $22(0.4)$ & $7(0.6)$ & 0.355 \\
\hline \multicolumn{5}{|l|}{ Use of antihypertensives } \\
\hline Use of all antagonist & $412(6.0)$ & $256(4.7)$ & 156(13) & $0.000^{*}$ \\
\hline Use of ACE inhibitors & 1278(19.3) & $937(17.2)$ & $341(29.3)$ & $0.000^{*}$ \\
\hline Use of beta blockers & $1787(27.0)$ & $1327(24.4)$ & $460(39.5)$ & $0.000^{*}$ \\
\hline Use of calcium antagonists & $867(13.1)$ & $579(10.6)$ & $288(24.7)$ & $0.000^{*}$ \\
\hline Use of diuretics & 1063(16.1) & $732(13.4)$ & $331(28.4)$ & $0.000^{*}$ \\
\hline Use of statins & $1145(17.3)$ & $879(16.1)$ & $266(22.8)$ & $0.035^{*}$ \\
\hline Use of ED medication & $389(5.9)$ & $282(5.1)$ & 107(9.1) & $0.010^{*}$ \\
\hline
\end{tabular}

Data are expressed as No. (\%) unless otherwise noted. SD: standard deviation, y: year. *1: Cardiovascular Diseases include K74 (angina pectoris), K75 (acute myocardial infarction), K76 (other chronic ischaemic heart diseases), K89 (TIA), and K90 (CVA). *2: Erectile Dysfunction includes: Y07 (symptoms sexual potential), *3: Use of medication for Lower Urinary tract symptoms, *4: Use of medication for Diabetes mellitus.

*: p-value significant $(<0.05)$.

example, for cardiovascular diseases [3,4]. In this study, we investigated 1165 men with LUTS. Based on the results, LUTS is not a factor that must be taken into account for the detection of CVD, in primary care.

\section{Interpretation of findings in relation to previously published work}

Other studies report the association between LUTS and CVD $[17,18,36]$. The results suggest that vascular risk factors seem to be associated with the presence and degree of LUTS, prostate size or outflow obstruction. Vascular diseases such as atherosclerosis and endothelial dysfunction in the pelvic vascular system are one of the possible mechanisms contributing to bladder dysfunction with age [17]. Increased sympathetic activity and/or a1-adrenoreceptor activity might be a common pathway for both hypertension and LUTS, and might explain the improvement in LUTS with the use of a1- adrenoreceptor antagonist [36].

Table 3 CVD status by age and LUTS status among the study population

\begin{tabular}{|c|c|c|c|c|c|c|c|c|}
\hline \multirow[b]{2}{*}{ CVD status } & \multicolumn{3}{|c|}{$\begin{array}{c}\text { No LUTS, } \mathrm{n}=5449 \\
N(\% \text { within presence of LUTS) }\end{array}$} & \multicolumn{3}{|c|}{$\begin{array}{c}\text { LUTS, } \mathrm{n}=1165 \\
N(\% \text { within abcence of LUTS) }\end{array}$} & \multicolumn{2}{|c|}{$C V D, n=1539$} \\
\hline & No CVD & $C V D$ & $\begin{array}{l}\text { Subtotal no } \\
\text { LUTS, } n \text { (\%) }\end{array}$ & No CVD & $C V D$ & $\begin{array}{l}\text { Subtotal } \\
\text { LUTS } n \text { (\%) }\end{array}$ & $\begin{array}{l}\text { Subtotal } \\
\text { CVD } n \text { (\%) }\end{array}$ & $\mathrm{p}$-value \\
\hline \multicolumn{9}{|l|}{ Age groups } \\
\hline $50-54$ yrs & 3015 (90.7) & 309 (9.3) & 3324 (61.0) & $223(85.1)$ & $39(14.9)$ & $262(22.5)$ & $348(22.6)$ & 0.003 \\
\hline $55-59$ yrs & $509(77.5)$ & $148(22.5)$ & $657(12.1)$ & $92(66.2)$ & 47 (33.8) & 139 (11.9) & 159 (10.3) & 0.005 \\
\hline $60-64$ yrs & $333(72.1)$ & $129(27.9)$ & $462(8.5)$ & $82(57.3)$ & $61(42.7)$ & $143(12.3)$ & $190(12.3)$ & 0.001 \\
\hline 65-69 yrs & $215(57.8)$ & $157(42.2)$ & $372(6.8)$ & $86(49.9)$ & $88(50.6)$ & $174(14.9)$ & $245(15.9)$ & 0.067 \\
\hline $70-78$ yrs & $317(50)$ & $317(50)$ & $634(11.6)$ & $203(45.4)$ & $244(45.4)$ & $447(38.4)$ & $561(36.5)$ & 0.137 \\
\hline All ages & 4389 (80.5) & $1060(19.5)$ & 5449 (100\%) & $686(58.9)$ & 479 (41.1) & 1165 (100\%) & 1539 (100\%) & 0.000 \\
\hline
\end{tabular}

LUTS: Lower Urinary Tract Symptoms, CVD: cardiovascular disease. 
Table 4 The association between LUTS and CVD from longitudinal analyses, final model

\begin{tabular}{lll}
\hline Outcome & Unadjusted & Multivariate adjusted * \\
\hline & $\mathrm{HR}(95 \% \mathrm{Cl}, \mathrm{p}$-value $)$ & $\mathrm{HR}(95 \% \mathrm{Cl}, \mathrm{p}$-value $)$ \\
$\mathrm{CVD}$ & $1.16(1.035-1.291, \mathrm{p} 0.010)$ & $0.921(0.824-1.030, \mathrm{p} \mathrm{0.150)}$ \\
\hline
\end{tabular}

*Variables in multivariate analysis: Hypertension, ACE inhibitors, All antagonists, beta blockers, Calcium antagonists.

Kim et al. found that men with 3 or more vascular risk factors were 3 times more likely to have moderate/severe LUTS than men without vascular risk factors (OR 3.6 (95\% CI 1.19-10.62, p0.024). However, these studies are mostly clinical studies [17-22]. There are often considerable methodological and population differences between them. This latter is an important point as we cannot generalise the results from other studies (all clinical- or community based studies) to the patient population of the GP. Also the cross-sectional setting of the studies makes them not suitable to analyse causal relationships.

Recently, a community-based retrospective, cross-sectional and longitudinal study into this relationship was carried out [25]. Wehrberger et al. concluded that men with severe LUTS have an increased risk of developing CVD. They investigated a large group of people with LUTS $(n=2092)$. However, the conclusions of their study were based on just $1 \%$ of the total study population. Another population based longitudinal study did not found an association between LUTS and CVD, but was especially focussed on nycturia as a subcategory of LUTS [37].

\section{Strengths and limitations}

The strength of our study is the longitudinal analysis, and the large cohort of 6615 men. Using data from electronic medical records from general practices makes it possible to compare the prevalence of CVD between different patient groups in the same study population. We also had information about the sequence of the diseases, LUTS and CVD events, and hence a possible relationship between LUTS and subsequent CVD could be taken into the statistical analyses.

According to previous articles about RNG data, this study population is representative for the Dutch population [38].

A limitation of this study is having access to large patient populations in a health registry with data that are not collected in a structural way. Patients are not measured periodically. Important confounders, such as dyslipidemia, smoking and obesity, are not always registered in the electronical medical records of GPs. For example, in this study dyslipidemia is more frequent in men with LUTS. However, the prevalence of dyslipidemia in all subjects is lower than the Dutch prevalence numbers [39]. Because we cannot exclude underregistration of cardiovascular risk factors, we chose not to draw any conclusions from this finding.
An additional investigation into medical files could yield some of the unknown information about cardiovascular risk factors, in a longitudinal study-setting.

Because of the absence of an ICPC code for LUTS, we assumed the presence of LUTS if one or more of these ICPC codes were identified (Table 1). Unfortunately, this did not always agree with the LUTS definition from other studies. As we did not measure the International Prostate Symptom Score (IPSS) of men with LUTS, we were unable differentiate between men with mild, moderate or severe LUTS.

Another factor that should be considered is the underreporting of LUTS, the so-called iceberg phenomenon: $[15,40,41]$ i.e. the reported incidence and population prevalence differ considerably (contact with GP for LUTS: from $4-9 \%$ up to $23 \%$ ) $[15,42]$. Consequently, fewer LUTS cases are identified by the GP than are actually present in the practice population. The lack of relationship established between LUTS and CVD might therefore be incorrect.

\section{Conclusions}

To the best of our knowledge, this is the first study that investigated the relationship between LUTS and cardiovascular diseases in primary care. It suggests that a GP does not have to complete a full cardiac risk profile in men who present with LUTS symptoms for the first time.

\section{Abbreviations}

LUTS: Lower urinary tract symptoms; CVD: Cardiovascular disease; RNG: Registration network groningen; GP: General practitioner; ED: Erectile dysfunction; ICPC: International classification of primary care; ATC: Anatomical therapeutic chemical; PY: Personyears; Cl: Confidential interval; HR: Hazard ratio; OR: Odds ratio.

\section{Competing interests}

The authors declare that they have no competing interests.

\section{Authors' contributions}

IIB: carried out the analysis and interpretation of data, and drafted the manuscript. BJK caried out the analysis and performed the statistical analysis, and helped to draft the manuscript. WK, KM, and JMN participated in the study design and coordination. WK helped to draft the manuscript and made contributions to conception and design of the study. All authors read and approved the final manuscript.

\section{Author details}

'Department of general practice, University of Groningen, University Medical Center Groningen, Antonius Deusinglaan 1, Groningen, AV 9713, Netherlands. ${ }^{2}$ Department of urology, University of Groningen, University Medical Center Groningen, Hanzeplein 1, Groningen, GZ 9713, Netherlands.

Received: 27 April 2013 Accepted: 3 January 2014

Published: 14 January 2014

\section{References}

1. Alwan A, Armstrong T, Bettcher D, Branca F, Chisholm D, Ezzati M, Garfield R, MacLean D, Mathers C, Mendis S, Poznyak V, Riley L, Cho Tang K, Wild C, WHO: 2008-2013 Action Plan for the Prevention and Control of nonCommunicable Diseases. Geneva Switzerland: WHO Press; 2008. ISBN 9789241597418.

2. Zakaria L, Aristotelis GA, Shabsigh R: Common conditions of the aging male: erectile dysfunction, benign prostatic hyperplasia, cardiovascular disease and depression. Int Urol Nephrol 2001, 33:283-292. 
3. Dekker JM, Alssema M, Janssen PGH, Van der Paardt Mt, Festen CCS, Van Oosterhout MJW, Van Dijk JL, Van der Weijden T, Gansevoort RT, Dasselaar J, Van Zoest F, Drenthen T, Walma EP, Goudswaard AN: NHG Guideline prevention of cardiometabolic diseases. Huisarts Wet 2011, 54(3):138-155.

4. Graham I, Atar D, Borch-Johnsen K, Boysen G, Burell G, Cifkova R, Dallongeville J, De Backer G, Ebrahim S, Gjelsvik B, Herrmann-Lingen C, Hoes A, Humphries S, Knapton M, Perk J, Priori SG, Pyorala K, Reiner Z, Ruilope L, Sans-Menendez S, Op Reimer WS, Weissberg P, Wood D, Yarnell J, Zamorano JL, Walma E, Fitzgerald T, Cooney MT, Dudina A, Vahanian A, et al: European guidelines on cardiovascular disease prevention in clinical practice: executive summary. Fourth Joint Task Force of the European Society of Cardiology and other societies on cardiovascular disease prevention in clinical practice (constituted by representatives of nine societies and by invited experts). Eur J Cardiovasc Prev Rehabil 2007, 14(2):1-40.

5. Ponholzer AA, Gutjahr GG, Temml CC, Madersbacher SS: Is erectile dysfunction a predictor for cardiovascular events or stroke? A prospective study using a validated questionnaire. Int J Impot Res 2010, 22(1):25-29

6. Miner M, Seftel AD, Nehra A, Ganz P, Kloner RA, Montorsi P: Prognostic utility of erectile dysfunction for cardiovascular disease in younger men and those with diabetes. Am Heart J 2012, 164(1):21-28.

7. Schouten BW, Bohnen AM, Bosch JL, Bernsen RM, Deckers JW, Dohle GR, Thomas S: Erectile dysfunction prospectively associated with cardiovascular disease in the Dutch general population: results from the Krimpen Study. Int J Impot Res 2008, 20(1):92-99.

8. Van der Linden MW, Westert GP, De Bakker DH, Schellevis FG: Tweede Nationale Studie naar ziekten en verrichtingen in de huisartspraktijk: klachten en aandoeningen in de bevolking en in de huisartspraktijk. Utrecht/Bilthoven: NIVEL/RIVM; 2004

9. Roberston C, Link CL, Onel E, Mazzetta C, Keech M, Hobbs R, Fourcade R, Kiemeney L, Lee C, Boyle P, Mc Kinlay JB: The impact of lower urinary tract symptoms and comorbidities on quality of life: the BACH and UREPIK studies. BJU Int 2007, 99:347-354.

10. Blanker MH, Bohnen AM, Groeneveld FPMJ, Prins A, Thomas S, Bosch JL: Correlates for erectile and ejaculatory dysfunction in older Dutch men: a community-based study. JAGS 2001, 49:436-442.

11. Gacci M, Eardley I, Giuliano F, Hatzichristou D, Kaplan SA, Maggi M, Mc Vary MT, Mirone V, Porst $H$, Roehrborn CG: Critical analysis of the relationship between sexual dysfunctions and lower urinary tract symptoms due to benign prostatic hyperplasia. Eur Urology 2011, 60:809-825.

12. Rosen RC, Wei JT, Althof SE, Seftel AD, Miner M, Perelman MA: Association of sexual dysfunction with lower urinary tract symptoms of $\mathrm{BPH}$ and BPH medical therapies: results from the BPH Registry. Urology 2009, 73:562-566

13. Wein AJ, Coyne KS, Tubaro A, Sexton CC, Kopp ZS, Aiyer LP: The impact of lower urinary tract symptoms on male sexual health: EpiLUTS. BJU Int 2009, 103(3):33-41.

14. Okkes IM, Oskam SK, Van Boven K, Lamberts H: EFP. Episodes of Care in Dutch Family Practice. In Epidemiological Data Based on the Routine use of the International Classification of Primary Care (ICPC) in the Transition Project of the Academic Medical Center/University of Amsterdam (1985-2003), ICPC in the Amsterdam Transition Project. CD rom. Edited by Okkes IM, Oskam SK, Lamberts H. Amsterdam, Netherlands: Academic Medical Center/University of Amsterdam, Department of Family Medicine; 2005.

15. Van Der Heide WK: General practitioners care for men with urine problems. In PhD thesis. University of Groningen, department of general practice; 2006.

16. Wolters R, Wensing M, Van Weel C, Van der Wilt GJ, Grol RP: Lower urinary tract symptoms: social influence is more important than symptoms in seeking medical care. BJU Int 2002, 90:655-61.

17. Ponholzer A, Temml C, Wehrberger C, Marszalek M, Madersbacher S: The association between vascular risk factors and lower urinary tract symptoms in both sexes. Eur Urol 2006, 50:581-586.

18. Ng CF, Wong A, Li ML, Chan SY, Mak SK, Wong WS: The prevalence of cardiovascular risk factors in male patients who have lower urinary tract symptoms. Hong Kong Med J 2007, 13:421-426.

19. Gibbons EP, Colen J, Nelson JB, Benoit RM: Correlation between risk factors for vascular disease and the American Urological Association symptom Score. BJU Int 2007, 99:97-100.

20. Litman HJ, Steers WD, Wei JT, Kupelian V, Link CL, McKinlay JB: Relationship of lifestyle and clinical factors to lower urinary tract symptoms: results from Boston area community health survey. Urology 2007, 70:916-921.
21. Kupelian V, Rosen RC, Link CL, McVary KT, Aiyer LP, et al: Association of urological symptoms and chronic illness in men and women: contributions of symptom severity and duration-results from the $\mathrm{BACH}$ survey. J Urol 2009, 181(2):694-700.

22. Sandfeldt $L$, Hahn RG: Cardiovascular risk factors correlate with prostate size in men with bladder outlet obstruction. BJU Int 2003, 92:64-68.

23. Michel MC, Heemann U, Schumacher H, Mehlburger L, Goepel M: Association of hypertension with symptoms of benign prostatic hyperplasia. J Urol 2004, 172:1390-1393.

24. Parsons JK: Benign prostatic hyperplasia and male lower urinary tract symptoms: epidemiology and risk factors. Curr Bladder Dysfunct Rep 2010, 5:212-218.

25. Wehrberger C, Temml C, Gutjahr G, Berger I, Rauchenwald M, Ponholzer A Madersbacher S: Is there an association between lower urinary tract symptoms and cardiovascular risk in men? A cross sectional and longitudinal analysis. Urology 2011, 78(5):1063-7.

26. Karatas OF, Bayrak O, Cimentepe E, Unal D: An insidious risk factor for cardiovascular disease: benign prostatic hyperplasia. Int J Cardiol 2010, 144(3):452.

27. Van der Veen WJ, Meyboom-de Jong B: Age and gender. In Oxford Textbook of Primary Medical Care. Edited by Jones R, Britten N, Culpepper L, Gass DA, Grol R, Mant D. Oxford: Oxford University Press; 2004.

28. Schellevis FG, Westert GP, De Bakker DH: The actual role of general practice in the Dutch health-care system: results of the Second Dutch National Survey of General Practice. J Public Health 2005, 5:265-269.

29. Lamberts H, Wood M, ICPC: International Classification of Primary Care. Oxford: Oxford University Press; 1987.

30. WHO Collaborating Centre for Drugs Statistics Methodology (Norway): Guidelines for ATC Classification and DDD Assignment. Oslo, Norway: The WHO Collaborating Centre; 2000.

31. Dantas AP, Jimenez-Altayo F, Vila E: Vascular aging: facts and factors. Front Vasc Physiol 2012, 325:1-2.

32. Jones C, Hill J, Chapple C: Guideline development group. Management of lower urinary tract symptoms in men: summary of NICE guidance. BMJ 2010, 340:c2354

33. NIH: Consensus statement on impotence. Int J Impot Res 1993, 5:181-199.

34. Twisk JWR: Applied Multilevel Analysis: A Practical Guide. Cambridge UK: Cambridge University Press; 2006.

35. Wilson PW, D'Agostino RB, Levy D, Belanger AM, Silbershatz H, Kannel WB: Prediction of coronary heart disease using risk factor categories. Circulation 1998, 97:1837-47.

36. Kim S, Jeong JY, Choi YJ, Kim DH, Lee WK, Lee SH, Lee SK: Association between lower urinary tracct symptoms and vascular risk factors in aging men: the hallym aging study. Korean J Urol 2010, 51:477-482.

37. Paans N, Van der Veen WJ, Van der Meer K, Bulstra SK, Van den Akker-Scheek I, Stevens M: Time spent in primary care for hip osteoarthritis patients once the diagnosis is set: a prospective observational study. BMC Fam Pract 2011, 12:48-2296. 12-48

38. Lightner DJ, Krambeck AE, Jacobson DJ, McGree ME, Jacobsen SJ, Lieber MM, Roger VL, Girman CJ, St Sauver JL: Nocturia is associated with an increased risk of coronary heart disease and death. BJU Int 2012, 110(6):848-53.

39. Wiersma T, Smulders YM, Stehouwer CD, Konings KT, Lanphen J: Summary of the multidisciplinary guideline on cardiovascular risk management (revision 2011). Ned Tijdschr Geneeskd 2012, 156(36):A5104.

40. Hannay DR: The 'iceberg' of illness and 'trivial' consultations. J R Coll Gen Pract 1980, 30:551-554

41. Last JM: The iceberg "Completing The Clinical Picture" in general practice. Lancet 1963, 7297:28-31.

42. Garraway WM, Russell EB, Lee RJ, Collins GN, McKelvie GB, Hehir M, Rogers AC, Simpson RJ: Impact of previously unrecognized benign prostatic hyperplasia on the daily activities of middle-aged and elderly men. Br J Gen Pract 1993, 43:318-21.

doi:10.1186/1471-2296-15-9

Cite this article as: Bouwman et al:: Are lower urinary tract symptoms in men associated with cardiovascular diseases in a primary care population: a registry study. BMC Family Practice 2014 15:9. 